\title{
Data, Models, and Decisions: How We Can Shape Our World by Not Predicting the Future
}

\author{
Niki Popper
}

\begin{abstract}
Modelling and simulation can be used for different goals and purposes. Prediction is only one of them, and, as this chapter highlights, it might not be the main goal-even if it was in the spotlight during the COVID-19 crisis. Predicting the future is a vanity. Instead, we aim to prevent certain events in the future by describing scenarios, or, even better, we try to actively shape the future according to our social, technological, or economic goals. Thus, modellers can contribute to debate and social discourse; this is one of the aims of Digital Humanism.
\end{abstract}

"I don't try to describe the future. I try to prevent it." This Ray Bradbury quote from 1977 was cited by Theodore Sturgeon in Emtsev and Parnov (1977, p. viii): "In a discussion of (Orwell's) book 1984, Bradbury pointed out that the world George Orwell described has little likelihood of coming about-largely because Orwell described it. 'The function of science fiction is not (only) to predict the future, but to prevent it.' Bradbury said.",

The use of modern simulation methods also often falls prey to the misunderstanding that prediction is its main goal. In my opinion, it is not our purpose to predict the future. Instead, we aim to prevent certain events in the future by describing scenarios or-even better-try to actively shape the future according to our social, technological, or economic goals. We can thereby contribute to discussions and social discourse; this is one of the intentions of Digital Humanism. One of the most important scientific contributions to achieving this aim has been the development of innumerable types of models that are fed with all kinds of data. This wealth rather complicates things...

\footnotetext{
${ }^{1}$ Theodore Sturgeon wrote this in the preface to a Russian science fiction book. One can, of course, concede that the idea of preventing disaster was probably more prevalent during the Cold War era than that of bringing about positive change, as compared to recent decades.
}

\footnotetext{
N. Popper $(\bowtie)$

Vienna University of Technology, Vienna, Austria

e-mail: nikolas.popper@tuwien.ac.at 
At first glance, the notions of shaping the future and of preventing undesired events from happening do not differ from each other. They both revolve around the fact that we usually want to not only predict the future but to actually change it (for the better). Some kinds of models, like the weather forecast, focus on prediction. We mostly just want to know how likely it is that we will need an umbrella and not why. Thus, the design of those kinds of models differs greatly from the ones that will be described in this chapter, i.e., those being used by my group in the ongoing COVID19 crisis. These are models that can show different possible outcomes for different decisions and are used to support the discussion of the available variety of strategies.

In January 2020, my group at TU Wien began applying our model of the virtual Austrian population, its interactions and connections to infrastructure, measures, and policies in order to model the COVID-19 crisis (Bicher et al. 2021a). We are now able to map different aspects of the COVID-19 crisis that interact with each other on an individual level. These are, among others, strategic aspects such as (A) setting and cancelling measures; (B) testing, screening, and isolation strategies; (C) vaccination; and (D) the development of new therapeutic concepts. From a systemic perspective, it is possible to implement (E) changes in viral properties (such as mutations), (F) changes in the population (e.g., through natural immunization or vaccination), or $(\mathrm{G})$ changes in environmental influences.

We have contributed our work to the Austrian government since March 2020. Initially, this support took the form of short-term predictions together with other research groups as joint action in the Austrian Prognosis Consortium (Bicher et al. 2021b). Subsequently, in addition, we started to communicate the relationships between measures, dynamics, decisions, and social and epidemiological outcomes. The main approaches have been vaccination programs (Jahn et al. 2021) and screening strategies and how they can shape society for better or worse.

During the COVID-19 crisis, we have learned that there are no technological solutions without integrating peoples' needs, weaknesses, hopes, and ambitions. Simulation, models, and decision tools have to be integrated into processes based on the foundations of Digital Humanism. We also need solutions in order to cope with the lack of transparent and reliable data that can be used for our models in accordance with the European Data Protection Regulation (GDPR).

Bradbury's statement refers to the fact that prediction can prevent a thing because we have become aware of it and take countermeasures. That is something where modelling can contribute. Modelling and simulation have to do more than sketch an "outcome," as science fiction does so well. Ideally, we also want to describe feasible ways to improve something in the future. To be able to do so, we need to understand interrelationships and describe causalities without ever leaving the safe ground of steady data. This is the fundamental concept of "decision support" as sought by politicians, managers, and others with the decision-taking powers.

Do we need accurate predictions in order to generate reliable decision support? Not necessarily. In fact, prediction can even be a hindrance in the process of change because it reinforces the impression that the future is already decided. Might 
Laplace's demon $^{2}$ (Laplace 1825, p. 4) have long been refuted already? While it is necessary to think and work in scenarios, we then also need to integrate these thoughts into the change process. Models can only be one piece of the puzzle of "decision support." They need to be embedded into the bigger picture, i.e., other processes.

In my experience, it is unavoidable to make use of a range of different established methodological approaches and, moreover, combine these to create tailor-made processes which make it possible to link the respective advantages and disadvantages of each method, laying the groundwork for "better decisions." I like to think of it as a gradual process with feedback loops:

(1) Get your data straight. In their first step, modellers collect and analyze data. Hypotheses are generated on the basis of data with the help of different methods, such as statistics or artificial intelligence. This approach makes it possible to make forecasts. During the COVID-19 crisis, early models allowed us to make basic statements about the current situation or to compare international developments. However, these concepts often mislead us into believing that we can continue to extrapolate developments. Moreover, we are still lacking valid and quality-assured data.

(2) Establish correlations and causalities and describe relationships. In this step, macroscopic models are used to couple the formalized data with causal or relational hypotheses. Examples of this approach have existed for many decades. Earliest works came from Norbert Wiener (Wiener 1961); Jay W. Forrester was a pioneer (Forrester 1973). System dynamics is one representative of the linkage between model representation through differential equations and the modelling process with non-mathematicians. The Limits to Growth. A Report for the Club of Rome's Project on the Predicament of Mankind by Meadows (Meadows et al. 1972) was an early example of the impact such approaches can have. It has enabled us to use system dynamics in order to develop our understanding of feedback loops and regulated systems in economics and ecology. With approaches such as system dynamics and differential equations, we can describe relationships and explain, for example, exponential behavior and logistic growth. While these aspects have particularly come to the fore in the COVID19 crisis, they have in fact been helping us to better understand the mechanisms of actions in therapy analysis for many years. Causal analysis has further facilitated this understanding since 2000 (Pearl 2000) by addressing issues

\footnotetext{
${ }^{2}$ Laplace wrote: "We ought then to regard the present state of the universe as the effect of its anterior state and as the cause of the one which is to follow. Given for one instant an intelligence which could comprehend all the forces by which nature is animated and the respective situation of the beings who compose it - an intelligence sufficiently vast to submit these data to analysis-it would be embrace in the same formula the movements of the greatest bodies of the universe and those of the lightest atom; for it, nothing would be uncertain and the future, as the past, would be present to its eyes."
} 
where traditional regression analyses fail in combination with time-varying confounding. ${ }^{3}$

(3) Describe emergent behavior. Finally, modelling with agents and networks makes it possible to describe dynamic socio-technical systems, such as when health system interventions are implemented in a heterogeneous population. Models try to use hypotheses and data in order to represent a given process both at the individual level and at the level of the real infrastructure. One example of this is the COVID-19 model developed by our group (Bicher et al. 2021a). These methods allow us to describe emergent behavior as well as frequently analyze and pre-estimate counter-intuitive behavior.

By being both complementary to and based upon each other, these three approaches to predicting the future contribute to an advanced understanding of the world as it is. They have enabled us to model, among other things, concrete decision support for vaccination prioritization (Jahn et al. 2021), screening strategies, as well as an assessment of ongoing immunization and its impact on spread dynamics (Rippinger et al. 2021).

Criticism of all three approaches is necessary and justified, but cannot be discussed in detail here. Very generally, data-driven models very easily trigger the hope for predictions. Causal models are often criticized for the lack of available means of validation. In the past, it has been almost impossible to link these models with data. COVID-19 was a global situation that revealed possibilities as well as weaknesses.

Sensible decision support for humans will in the future hinge on a combination of all these approaches. This is a key realization. Agent-based models are particularly well suited for integrating new data structures on an ongoing basis. During the COVID-19 crisis, this included epidemiological data, vaccination data, mobility data, information on home office use, school closures, weather data, and many more. The effort it takes to verify, validate, calibrate, and consider their reproducibility is enormous, but it is worth it. In order to really achieve the desired results, these agent-based models need to be combined with data-driven and macroscopic approaches. In Austria, the COVID-19 crisis inspired the formation of a consortium early on, so that all approaches could be compared (Bicher et al. 2021b). Together, we cover a range of methods to be able to answer different research questions.

One of the tasks and aspects of modelling is, of course, forecasting. The models that are good at forecasting are, however, different from those that are used for strategy development. Each question needs an appropriate model and every model needs the right questions. We have now come full circle: we can output the corresponding data from agent-based models as synthetic data sets (Popper et al. 2021 ) in order to examine the very models we have used with statistical methods.

\footnotetext{
${ }^{3}$ This means that there are variables that are simultaneously confounders (common causes of treatment and outcome) and intermediate steps, i.e., on the causal chain treatment that leads to an outcome. In other words: Confounders are also affected by treatment. It is difficult to determine when one has identified "sufficient" causal chains.
} 
The gathering and handling of raw data, including a true understanding of the patterns and relationships therein, are undoubtedly vital to establish a solid basis for models. However, when a model aims to provide decision support, we must also be able to identify, represent, and reproduce the dynamics of a system-i.e., the behavior of the population. That is what makes it possible to not only predict future events but actually understand their underlying reasons.

Like other philosophical problems, Laplace's demon will continue to occupy our thoughts. We might even want this particular demon to act as our sparring partner. We will continue to ponder what purpose models can serve exactly and how stochasticity plays out in different models and "if-then" predictions. Also, we might want to have a closer look at those who gather the data, finding correlations and describing emergent behaviors.

In the end, we have to be aware of our limits and always keep in mind what our form of decision-taking support can actually contribute:

A few years ago, I presented an early version of the agent-based network model that we are currently using in the context of COVID-19 at a major meeting on the issue of influenza vaccination strategy. A medical professional approached me after the presentation and asked triumphantly: "Can you tell me now how many patients with the flu we can expect to present next year on the 17th of March?". My answer was: "No, I can't-you've got me there! But that knowledge would be utterly pointless, anyway. What we can do with our model, however, is to tell you which strategy you can use in order to minimise the number of infected people, or, indeed, to produce maximum damage."

\section{References}

Bicher M., Rippinger C., Urach C., Brunmeir D., Siebert U., Popper N. (2021a) Evaluation of Contact-Tracing Policies Against the Spread of SARS-CoV-2 in Austria - An Agent-Based Simulation accepted in Medical Decision Making, https://doi.org/10.1101/2020.05.12. 20098970

Bicher M., Zuba M., Rainer L., Bachner F., Rippinger C., Ostermann H., Popper N., Thurner N., Klimek P. (2021b) Supporting Austria through the COVID-19 Epidemics with a Forecast-Based Early Warning System, medRxiv 2020.10.18.20214767; https://doi.org/10.1101/2020.10.18. 20214767

Emtsev M. and Parnov E. (1977) World Soul, Introduction by Theodore Sturgeon, page viii, translated from Russian by Antonina W. Bouis, Macmillan Publishing Co., New York, researched at https:/quoteinvestigator.com/2010/10/19/prevent-the-future/

Forrester J.W., (1973) World Dynamics. Cambridge, Mass.: Wright-Allen Press.

Jahn B., Sroczynski G., Bicher M., Rippinger C., Mühlberger N., Santamaria J., Urach C., Schomaker M., Stojkov I., Schmid D., Weiss G., Wiedermann U., Redlberger-Fritz M., Druml C., Kretzschmar M., Paulke-Korinek M., Ostermann H., Czasch C., Endel G., Bock W., Popper N. and Siebert U. (2021) "Targeted COVID-19 Vaccination (TAV-COVID) Considering Limited Vaccination Capacities-An Agent-Based Modeling Evaluation," Vaccines, vol. 9, no. 5, p. 434, Apr. 2021, https://doi.org/10.3390/vaccines9050434

Laplace P.S. (1825) Essai philosophique sur les probabilités , A Philosophical Essay on Probabilities translated from French by Frederick Wilson Truscott and Frederick Lincoln Emory, John 
Wiley \& Son, Chapman \& Hall, 1902, https://bayes.wustl.edu/Manual/laplace_A_philosophi cal_essay_on_probabilities.pdf

Meadows, Donella H; Meadows, Dennis L; Randers, Jørgen; Behrens III, William W (1972) The Limits to Growth; A Report for the Club of Rome's Project on the Predicament of Mankind. New York: Universe Books. ISBN 0876631650. Retrieved 26 November 2017.

Pearl J. (2000) Causality. Cambridge university press.

Popper N., Zechmeister M., Brunmeir D., Rippinger C., Weibrecht N., Urach C., Bicher M., Schneckenreither G., Rauber A. (2021) Synthetic Reproduction and Augmentation of COVID-19 Case Reporting Data by Agent-Based Simulation, Data Science Journal 20(1), https://doi.org/10.5334/dsj-2021-016

Rippinger, C., Bicher, M., Urach, C. et al. (2021) Evaluation of undetected cases during the COVID-19 epidemic in Austria. BMC Infect Dis 21, 70, https://doi.org/10.1186/s12879-02005737-6

Wiener N. (1961) Cybernetics: Or Control and Communication in the Animal and the Machine. Paris, (Hermann \& Cie) \& Camb. Mass. (MIT Press) ISBN 978-0-262-73009-9; 1948, 2nd revised ed. 1961.

Open Access This chapter is licensed under the terms of the Creative Commons Attribution 4.0 International License (http://creativecommons.org/licenses/by/4.0/), which permits use, sharing, adaptation, distribution and reproduction in any medium or format, as long as you give appropriate credit to the original author(s) and the source, provide a link to the Creative Commons license and indicate if changes were made.

The images or other third party material in this chapter are included in the chapter's Creative Commons license, unless indicated otherwise in a credit line to the material. If material is not included in the chapter's Creative Commons license and your intended use is not permitted by statutory regulation or exceeds the permitted use, you will need to obtain permission directly from the copyright holder. 